\title{
Dimethyl Sulfate
}

National Cancer Institute

\section{Source}

National Cancer Institute. Dimethyl Sulfate. NCI Thesaurus. Code C44377.

An odorless, corrosive, oily liquid with an onion-like odor that emits toxic fumes upon heating. Dimethyl sulfate is used in industry as a methylating agent in the manufacture of many organic chemicals. Inhalation exposure to its vapors is highly irritating to the eyes and lungs and may cause damage to the liver, kidney, heart and central nervous system, while dermal contact causes severe blistering. It is a possible mutagen and is reasonably anticipated to be a human carcinogen based on evidence of carcinogenicity in experimental animals. ( $\mathrm{NCl05)}$ 